\title{
Brushless Field Excitation Scheme for Wound Field Synchronous Machines
}

\author{
Syed Sabir Hussain Bukhari $\left.{ }^{1,2}{ }^{(}\right)$, Ghulam Jawad Sirewal ${ }^{3}\left(\mathbb{C}\right.$, Faheem Akhtar Chachar ${ }^{1}(\mathbb{D}$ \\ and Jong-Suk Ro ${ }^{2, *(D)}$ \\ 1 Department of Electrical Engineering, Sukkur IBA University, Sukkur 65200, Pakistan; \\ sabir@iba-suk.edu.pk (S.S.H.B.); faheem.akhtar@iba-suk.edu.pk (F.A.C.) \\ 2 School of Electrical and Electronics Engineering, Chung-Ang University, Seoul 06910, Korea \\ 3 Department of Electrical and Electronic Engineering, Hanyang University, Ansan 426-791, Korea; \\ jawadsirewal1@gmail.com \\ * Correspondence: jongsukro@gmail.com
}

Received: 7 August 2020; Accepted: 20 August 2020; Published: 25 August 2020

\begin{abstract}
A new harmonic field excitation technique for the brushless operation of wound field synchronous machines (WFSMs) is proposed in this paper. The proposed scheme involves conventional three-phase and single-phase inverters operating at different frequencies and supply input current to the armature winding simultaneously. This results in a composite output current of the inverters, which contains fundamental as well as the third harmonic current components. The fundamental is utilized to develop the stator field, on the other hand, the third harmonic is used for developing the pulsating magnetomotive force (MMF) in the airgap. This MMF produces a harmonic current in the harmonic winding of the rotor which is later rectified to inject field current to the rotor field winding. The theoretical analysis of the proposed technique is supported using 2-D finite element analysis (FEA).
\end{abstract}

Keywords: brushless operation; harmonic field excitation; synchronous machines; wound field machines

\section{Introduction}

Permanent magnet (PM) machines have a vast range of applications owing to their high efficiency, power density, power factor, and torque density capabilities [1-6]. Moreover, they do not require any extra exciter, brushes, or slip rings for their field excitation. This makes PM machines compact as compared to the classical synchronous machines which require complex and bulky field excitation mechanisms that involve exciters installed on the shaft of the machine. Besides these advantages, there are a few fundamental deficiencies such as unadjustable flux and risk of loss excitation associated with PM machines. In addition, the cost of rare-earth magnets used in PM machines has increased to a very high level. This motivated the researchers to search for other options such as reluctance machines [7] and brushless wound field synchronous machines (BL-WFSM).

Several researchers have presented different field excitation schemes to avoid the use of expensive PM material, brushes and slip rings and to obtain the brushless operation for WFSMs. In general, these schemes involve a distinct harmonic winding placed in the rotor periphery along with the main rotor winding, and a supplementary winding installed in the stator in addition to the armature winding. The key role of the supplementary or auxiliary winding in such arrangements is to achieve an additional MMF in the airgap. This MMF is used to generate a harmonic current in the harmonic winding of the rotor that is later rectified to provide DC current to the main rotor field winding to obtain the rotor field. As the rotor field interacts with the main stator field it develops torque. 
Several techniques have been proposed by the researchers to modify the conventional WFSM with minimum modifications and realize maximum advantages. In [8-10], the authors proposed brushless techniques in which a sub-harmonic MMF component is produced besides the fundamental by injecting currents into the two different sections of the armature winding. In one of such studies, two inverters were used for this purpose. These inverters supplied two unique magnitudes of currents to the armature winding, which was installed with a distinct star connection and was symmetrically distributed in two halves of the stator. The higher harmonic MMF generated through this arrangement was generated in the harmonic winding of the rotor and rectified to produce direct current for the rotor field winding. Later on, the same technique was realized by using a single inverter. However, in this case, the number of turns in each portion of the armature winding was different from each other. This technique generates higher harmonics due to the different magnitude of currents in two different parts of the armature winding, which adversely influence the performance of the machine. In [7], the authors proposed a brushless filed excitation technique involving two inverters connected to the armature winding in parallel. The inverters were operating at -180 degrees phase shift and were connected and disconnected alternatively after each cycle using the thyristor switches. The composite output of this arrangement results in a waveform comprising of fundamental and third harmonic components. The fundamental is utilized to generate the main armature field; however, the third harmonic is utilized to generate harmonic current in the harmonic winding of the rotor. The generated harmonic current is rectified for rotor field excitation. Although this technique achieves brushless operation for WFSM, the usage of thyristor switches with both inverters makes the system bulky and costly.

In [11], the authors developed a modified inverter topology to supply the same composite first-third harmonic current waveform for the armature winding as discussed in the previous case. However, this technique required a unique inverter design along with a sophisticated control technique. In [12], a brushless field excitation technique based on the installation of supplementary thyristors connected with the armature winding was proposed. The provided thyristor switches were operating at near zero-crossing of each phase current. This arrangement generated a zero-sequence third harmonic for the armature winding, which was then induced in the harmonic winding to achieve the brushless operation of WFSM. However, this technique requires a complicated drive system which increases the volume of the drive system. Furthermore, it requires several alterations to the structure of the machine.

This paper suggests a new harmonic field excitation technique for the brushless operation of WFSMs which involves customary three-phase and single-phase inverters. The three-phase inverter is connected to the armature and injects three-phase currents to the armature winding. The single-phase inverter is connected to the armature star-connected common point. The inverters operate at different frequencies and supply input armature currents to generate a unique armature current shape. The composite output of the inverter's currents for the armature winding contains the fundamental as well as the third harmonic. The fundamental is utilized to develop the stator field, whereas the third harmonic component is employed for developing the pulsating MMF in the airgap. This MMF generates a harmonic current in the harmonic winding of the rotor that is later rectified using a full-bridge diode rectifier to provide DC current to the field winding of the rotor to develop the rotor field. The generated rotor field as it interacts with the stator field develops torque.

\section{Proposed Topology and Its Operating Principle}

The proposed topology and its operating principle are elaborated as under:

\subsection{Proposed Topology}

The proposed topology as presented in Figure 1a consists of three-phase and single-phase inverters. These inverters are connected to the armature winding and operate simultaneously; however, the currents they supply have different frequencies, i.e., $60-\mathrm{Hz}$ and $180-\mathrm{Hz}$, respectively. The three-phase inverter is connected to the armature winding and supplies current at the frequency of $60-\mathrm{Hz}$, whereas the single-phase inverter is connected to the star-connected armature winding's common point and injects the 
current at $180-\mathrm{Hz}$ frequency. The main reason behind operating two inverters at two different frequencies is to develop a unique shape for the armature currents. This shape of the armature currents comprises of the fundamental as well as the third harmonic current component that results in fundamental and third harmonic MMF in the airgap of the machine. The third harmonic MMF is employed to generate current in the harmonic winding of the rotor. The harmonic winding in this case has eight poles. However, the generated current in the harmonic winding has six times the frequency of the fundamental armature current and two times the frequency of the third harmonic current component. The generated harmonic current is rectified to deliver DC current to the rotor field winding. This current produces the main rotor field which interacts with the armature field generated by the equal number of armature poles, producing torque. To confirm the operation of the proposed topology a 4-pole, 36-slot machine was employed. This machine model is presented in Figure 1b. The employed 36-slot double-layered armature winding, and the rotor harmonic and field windings configuration, is explained in Figure $2[13,14]$.

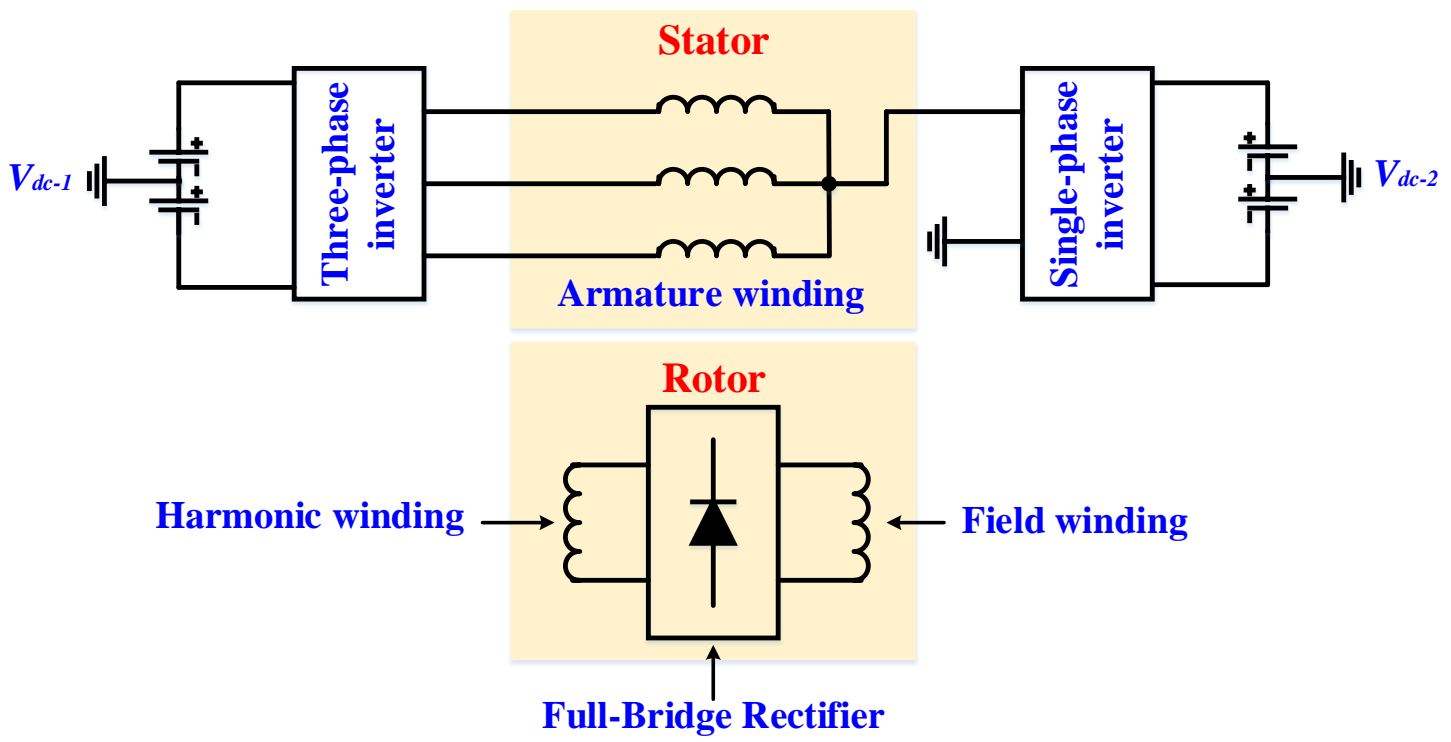

(a)

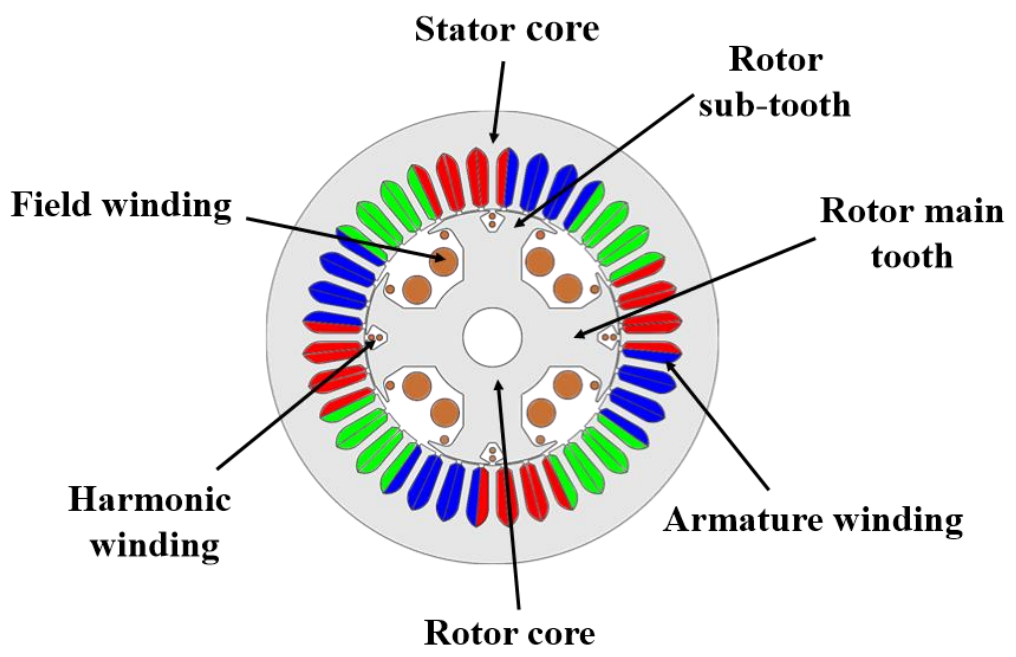

(b)

Figure 1. (a) Proposed topology and (b) machine model. 


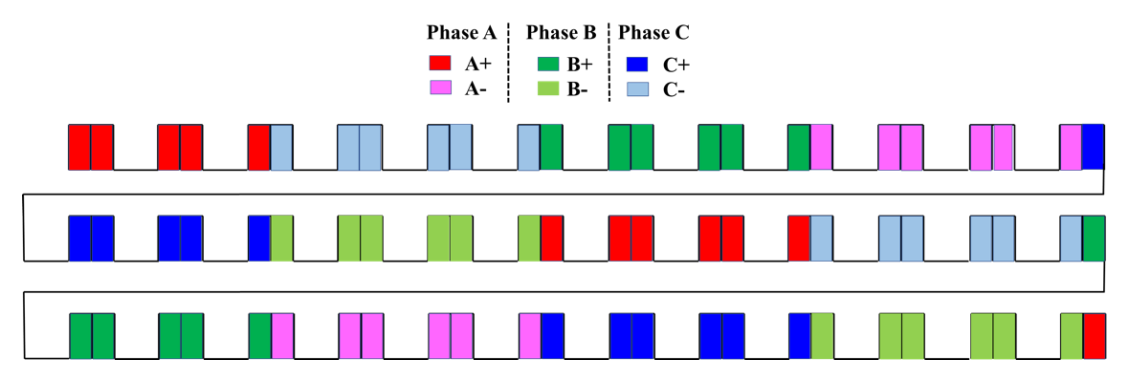

Figure 2. Armature and rotor windings configuration.

\subsection{Operating Principle}

Two customary inverters, i.e., the three-phase inverter and single-phase inverter, are used to supply the armature current $\left(I_{a b c}\right)$ to the machine. The three-phase inverter supplies $10 \mathrm{~A}$ (peak) current at the frequency of $60-\mathrm{Hz}$, i.e., the fundamental current component, to the armature winding; however, the single-phase inverter which is connected to the star-connected armature winding's common point supplies $10 \mathrm{~A}$ (peak) current at the frequency of $180-\mathrm{Hz}$, i.e., the third harmonic current component. Figure 3a illustrates the output current of the three-phase inverter $\left(I_{I N V-1}\right)$. The output current of the single-phase inverter $\left(I_{I N V-2}\right)$ is shown in Figure 3b. As the two inverters are operating at different output frequencies, the composite output of both inverters contains fundamental as well as third harmonic current components. The third harmonic current component generates current in the 8-pole rotor harmonic winding which will later be employed for rotor field excitation after the rectification. Figure $3 c$ shows the composite shape of the three-phase armature current $\left(I_{a b c}\right)$. To illustrate the harmonic contents of the armature current, an FFT (Fast Fourier Transform) plot is demonstrated in Figure 4 which indicates the two components, i.e., fundamental and third harmonic components, of the armature current of phase A. This figure shows that the magnitude of the third harmonic component is around $2.5 \mathrm{~A}$, whereas the magnitude of the fundamental of the armature currents is $10 \mathrm{~A}$.

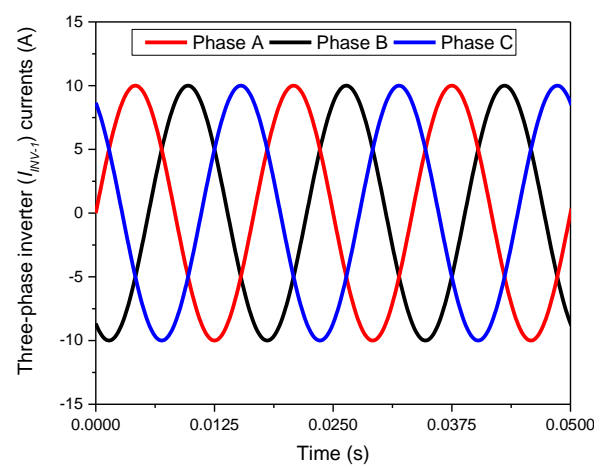

(a)

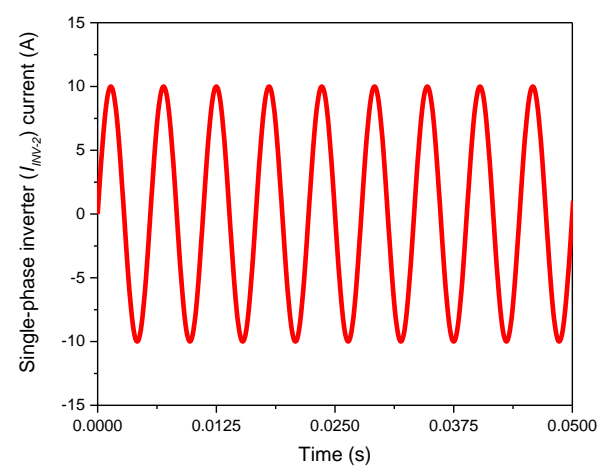

(b)

Figure 3. Cont. 


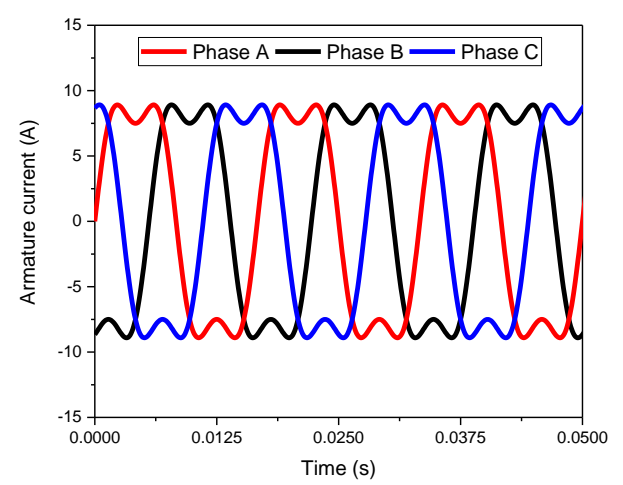

(c)

Figure 3. (a) Three-phase inverter, (b) single-phase inverter, and (c) armature currents.

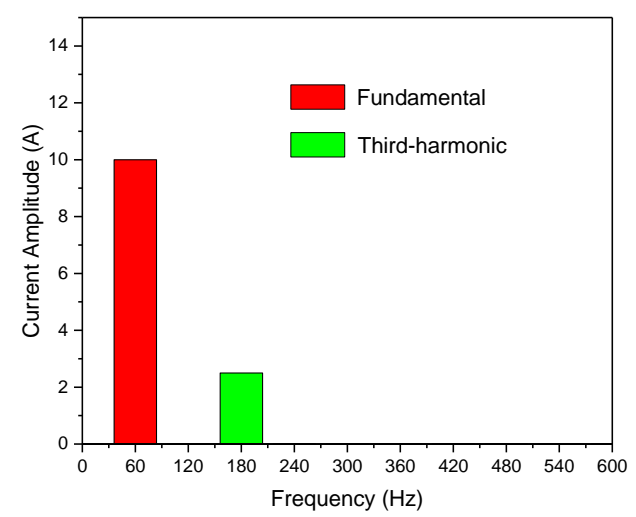

Figure 4. FFT plot for phase A of the armature currents.

The composite output currents of three-phase and single-phase inverters as given by (1):

$$
\begin{gathered}
i_{a}=I(\sin \omega t+n \sin 3 \omega t) \\
i_{b}=I\left[\sin \left(\omega t-\frac{2 \pi}{3}\right)+n \sin 3\left(\omega t-\frac{2 \pi}{3}\right)\right] \\
i_{c}=I\left[\sin \left(\omega t+\frac{2 \pi}{3}\right)+n \sin 3\left(\omega t+\frac{2 \pi}{3}\right)\right]
\end{gathered}
$$

Here $n$ is the weightage per third harmonic component. The above input armature current results in an MMF which can be calculated using the following equation:

$$
\begin{gathered}
F_{a}=i_{a} N_{\phi}\left[\sin \theta_{e}\right] \\
F_{b}=i_{b} N_{\phi}\left[\sin \left(\theta_{e}-\frac{2 \pi}{3}\right)\right] \\
F_{c}=i_{c} N_{\phi}\left[\sin \left(\theta_{e}+\frac{2 \pi}{3}\right)\right]
\end{gathered}
$$

Here $N_{\phi}$ is the number of turns per phase, $\theta_{e}=\omega t+\theta_{o}, \theta_{e}$ is the electrical angle, and $\theta_{o}$ is the initial position of the rotor.

The net MMF generated due to the three-phase input armature currents is given by Equation (3):

$$
F_{a b c}\left(\theta_{e}, i_{a b c}\right)=\frac{3}{2} I_{1} N_{\psi 1} \cos \left(\omega t-\theta_{e}\right)+I_{3} N_{\psi 1} \cos 3\left(\omega t+\theta_{e}\right)
$$


The pulsating third harmonic MMF component shown in Equation (3) is generated in the harmonic winding of the rotor as:

$$
\lambda_{h}=\frac{N_{h} N_{\psi 1}\left(\frac{3}{2} I_{1} \cos \left(\omega t-\theta_{e}\right)+n I_{3} \cos \left(3 \omega t+3 \theta_{e}\right)\right)}{R_{g}}
$$

Here $N_{h}$ is the number of turns of the rotor harmonic, and $R_{g}$ is the reluctance of the airgap.

Equation (5) is used to calculate the magnitude of the generated voltages in the rotor harmonic winding.

$$
e m f_{h}=6 \frac{d \lambda_{h}}{d t}=\frac{18 N_{h} N_{\psi 1} I_{3} \omega \sin 3\left(2 \omega t+\theta_{0}\right)}{R_{g}}
$$

The generated harmonic current is rectified and supplied to the rotor main field winding to achieve the proposed brushless operation for WFSM.

The described operating principle of the proposed brushless technique for WFSM is illustrated in Figure 5.

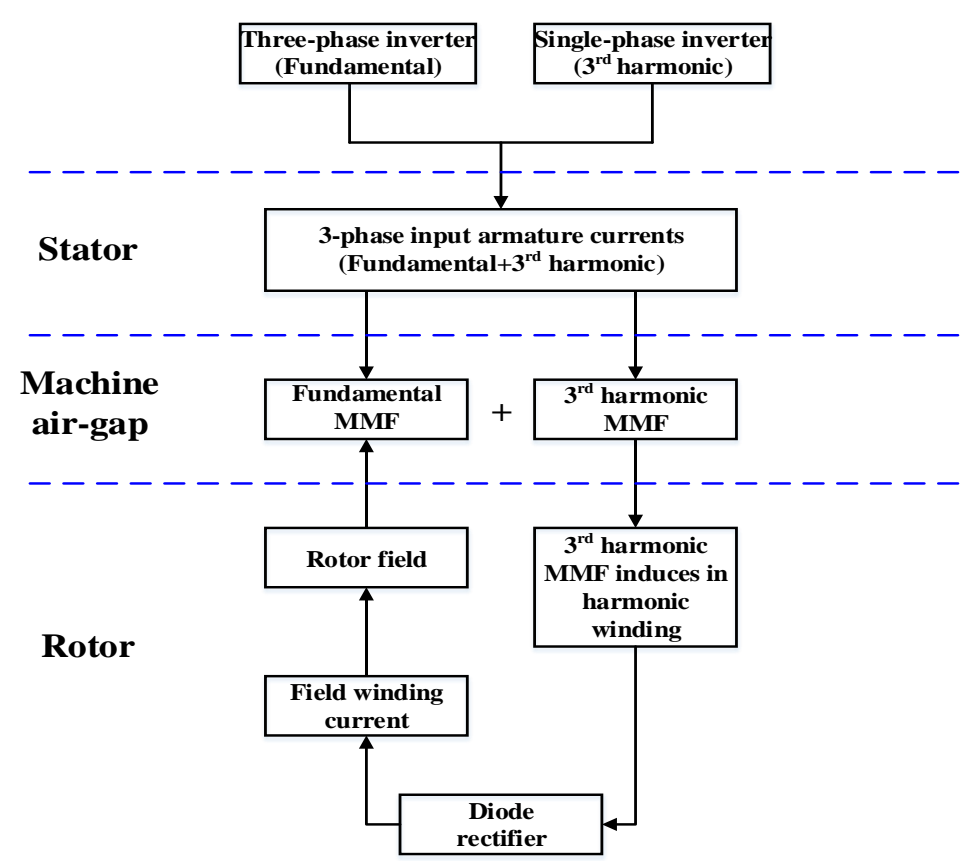

Figure 5. Working principle of the proposed brushless WRSM.

\section{Finite Element Analysis}

To validate the proposed brushless filed excitation technique for WFSM, the finite element method (FEM) was used. The parameters of the machine are listed in Table 1. The structure of the machine was implemented as discussed in [7]. The armature winding was supplied with a three-phase input current of $10 \mathrm{~A}$ (peak) at $60-\mathrm{Hz}$, and single-phase input current of $10 \mathrm{~A}$ (peak) at 180-Hz. As the input armature current comprised of the fundamental and third harmonic, the fundamental component generated the main armature field; however, the third harmonic current component generated 12-pole harmonic current in the harmonic winding of the rotor. This harmonic current was rectified to inject the excitation current to the rotor filed. The simulations were performed for $1.5 \mathrm{~s}$ using JMAG-Designer 18.1. The magnetic field density plot achieved during these simulations along with the three-phase flux linkages are presented in Figure $6 a, b$, respectively. The magnetic field density plot shows that the machine was operating under the saturation level. The induced harmonic current along with the rectified field current is demonstrated in Figure 7a. Figure $7 \mathrm{~b}$ illustrates the output torque of the 
machine. The average torque achieved during the complete simulation time was around $14.372 \mathrm{Nm}$ with a torque ripple of $66 \%$ as shown in Table 2.

Table 1. Machine specifications.

\begin{tabular}{cc}
\hline Attribute & Value \\
\hline Rated power & $2.5 \mathrm{~kW}$ \\
Speed & $1800 \mathrm{rpm}$ \\
Stator outer/inner diameter & $177 \mathrm{~mm} / 100 \mathrm{~mm}$ \\
Airgap & $0.5 \mathrm{~mm}$ \\
Rotor diameter & $99 \mathrm{~mm}$ \\
Shaft diameter & $23 \mathrm{~mm}$ \\
Machine poles/Stator slots & $4 / 36$ \\
Rotor main teeth/sub-teeth & $4 / 8$ \\
Sarmonic and field winding number of turns & $9 / 150 \mathrm{turns}$ \\
Stack length & $80 \mathrm{~mm}$ \\
\hline
\end{tabular}

Table 2. Machine performance.

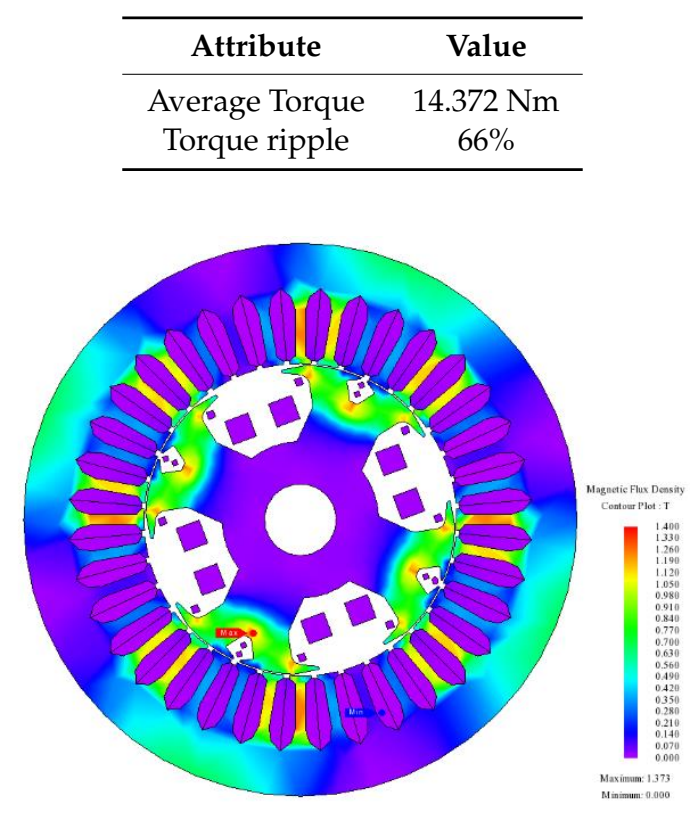

(a)

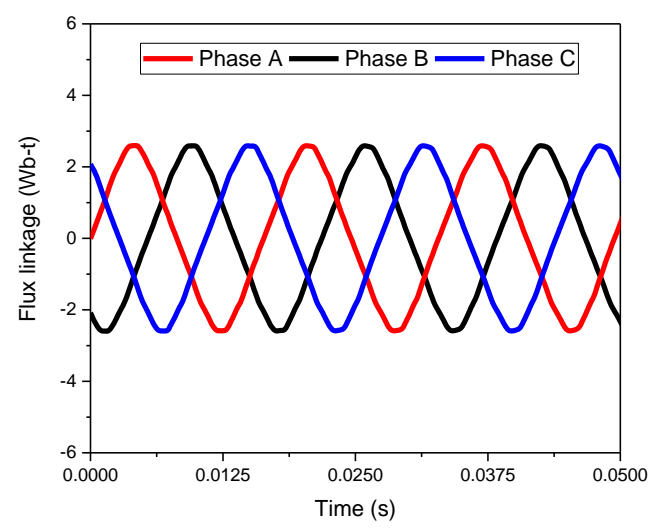

(b)

Figure 6. (a) Flux density distribution plot and (b) flux linkage. 


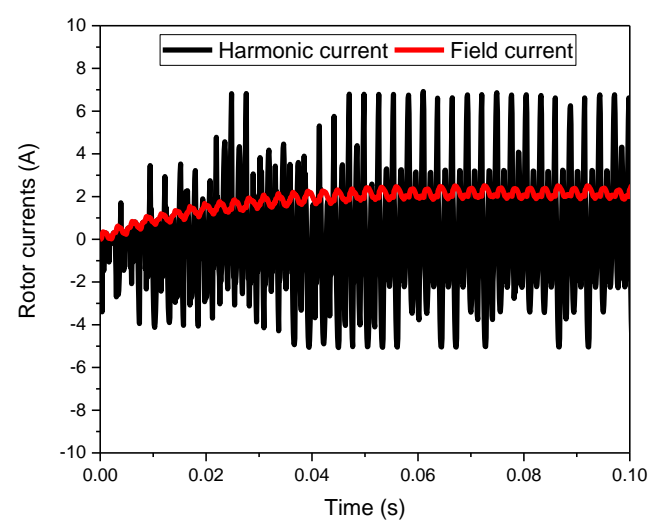

(a)

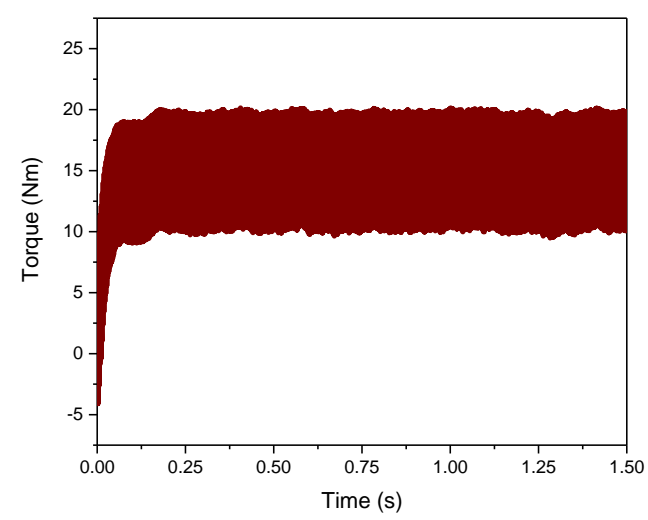

(b)

Figure 7. (a) Harmonic and field currents and (b) output torque.

\section{Conclusions}

A brushless field excitation technique for WFSMs was proposed in this paper. Two inverters, i.e., three-phase and single-phase inverters, that were connected to the armature winding and were supplying output current of frequencies were used to generate a unique composite armature current shape. The composite armature current was comprised of fundamental and third harmonic current components that produced fundamental and third harmonic MMF in the airgap. The pulsating third harmonic MMF was utilized to generate harmonic current in the 8-pole harmonic winding. The harmonic current was rectified to inject DC current to the rotor field winding. The field current and torque were provided to realize the idea.

Unlike the conventional brushless techniques for WFSM, the proposed technique is simple as it involves conventional inverters that do not require any complex control scheme. Furthermore, the proposed technique involves a single-phase inverter which makes it cost-effective as compared to the available dual inverter based brushless WFSM topologies in literature. In addition, the proposed BL-WFSM topology does not require any modification in the machine structure.

Author Contributions: Conceptualization, S.S.H.B. and G.J.S.; funding acquisition, J.-S.R.; investigation, S.S.H.B., F.A.C. and G.J.S.; writing-review and editing, S.S.H.B. All authors have read and agreed to the published version of the manuscript.

Funding: This research was supported in part by Basic Science Research Program through the National Research Foundation of Korea funded by the Ministry of Education (2016R1D1A1B01008058), by Human Resources Development (No. 20204030200090) of the Korea Institute of Energy Technology Evaluation and Planning (KETEP) grant funded by the Korea government Ministry of Trade, Industry and Energy, and by Korea Research Fellowship Program through the National Research Foundation (NRF) of Korea funded by the Ministry of Science and ICT (2019H1D3A1A01102988).

Conflicts of Interest: The authors declare no conflict of interest. 


\section{References}

1. Ayub, M.; Sirewal, G.J.; Bukhari, S.S.H.; Kwon, B.-I. Brushless wound rotor synchronous machine with third-harmonic field excitation. Electr. Eng. 2020, 102, 259-265. [CrossRef]

2. Bukhari, S.S.H.; Sirewal, G.J.; Ayub, M.; Ro, J.-S. A New Small-Scale Self-Excited Wound Rotor Synchronous Motor Topology. IEEE Trans. Magn. 2020, 1. [CrossRef]

3. An, Q.; Gao, X.; Yao, F.; Sun, L.; Lipo, T. The structure optimization of novel harmonic current excited brushless synchronous machines based on open winding pattern. In Proceedings of the 2014 IEEE Energy Conversion Congress and Exposition (ECCE), Pittsburgh, PA, USA, 14-18 September 2014; pp. 1754-1761.

4. Bukhari, S.S.H.; Jawad, G.; Chachar, F.A.; Ro, J.-S. Dual-Inverter-Controlled Brushless Operation of Wound Rotor Synchronous Machines Based on an Open-Winding Pattern. Energies 2020, 13, 2205. [CrossRef]

5. Memon, A.A.; Shaikh, M.M.; Bukhari, S.S.H.; Ro, J.-S. Look-up Data Tables-Based Modeling of Switched Reluctance Machine and Experimental Validation of the Static Torque with Statistical Analysis. J. Magn. 2020, 25, 233-244. [CrossRef]

6. Khan, S.; Bukhari, S.S.H.; Ro, J.-S. Design and Analysis of a 4-kW Two-Stack Coreless Axial Flux Permanent Magnet Synchronous Machine for Low-Speed Applications. IEEE Access 2019, 7, 173848-173854. [CrossRef]

7. Ali, Q.; Bukhari, S.S.H.; Atiq, S. Variable-speed, sub-harmonically excited BL-WRSM avoiding unbalanced radial force. Electr. Eng. 2019, 101, 251-257. [CrossRef]

8. Ali, Q.; Lipo, T.A.; Kwon, B.-I. Design and Analysis of a Novel Brushless Wound Rotor Synchronous Machine. IEEE Trans. Magn. 2015, 51, 1. [CrossRef]

9. Ayub, M.; Hussain, A.; Jawad, G.; Kwon, B.-I. Brushless Operation of a Wound-Field Synchronous Machine Using a Novel Winding Scheme. IEEE Trans. Magn. 2019, 55, 1-4. [CrossRef]

10. Ayub, M.; Atiq, S.; Sirewal, G.J.; Kwon, B.-I. Fault-Tolerant Operation of Wound Field Synchronous Machine Using Coil Switching. IEEE Access 2019, 7, 67130-67138. [CrossRef]

11. Ayub, M.; Bukhari, S.S.H.; Jawad, G.; Kwon, B.-I. Brushless wound field synchronous machine with third-harmonic field excitation using a single inverter. Electr. Eng. 2019, 101, 165-173. [CrossRef]

12. Jawad, G.; Ali, Q.; Lipo, T.A.; Kwon, B.-I. Novel Brushless Wound Rotor Synchronous Machine with Zero-Sequence Third-Harmonic Field Excitation. IEEE Trans. Magn. 2016, 52, 1-4. [CrossRef]

13. Yao, F.; An, Q.; Sun, L.; Lipo, T.A. Performance Investigation of a Brushless Synchronous Machine with Additional Harmonic Field Windings. IEEE Trans. Ind. Electron. 2016, 63, 6756-6766. [CrossRef]

14. Yao, F.; An, Q.; Gao, X.; Sun, L.; Lipo, T.A. Principle of Operation and Performance of a Synchronous Machine Employing a New Harmonic Excitation Scheme. IEEE Trans. Ind. Appl. 2015, 51, 3890-3898. [CrossRef] 